\title{
Viscous compression model for estimating the depth of new snow
}

\author{
Yuji Kominami, ${ }^{1}$ Yasoichi Endo, ${ }^{2}$ Shoji Niwano, ${ }^{2}$ Syuichi Ushioda ${ }^{3}$ \\ ${ }^{1}$ Kansai Research Center, Forestry and Forest Products Research Institute, Momoyama Town, Fushimi, Kyoto 612, Japan \\ ${ }^{2}$ Tohkamachi Experiment Station, Forestry and Forest Products Research Institute, Tohkamachi City, Niigata 948, Japan \\ ${ }^{3}$ Kaijyo Corporation, 3-1-5 Sakae Town, Hamura City, Tokyo 205, Japan
}

\begin{abstract}
This paper describes a method for estimating the depth of new snow, using hourly data of total snow depth and precipitation. As the snow cover is compacted continuously due to its own weight, the depth of new snow deposited since the previous time-step to the present time is given by a difference between the height of the present snow surface and the present compacted height of the previous snow surface. Thus, based on viscous compression theory and an empirical relation between compressive viscosity and the density of snow, an equation has been derived to compute the time variation of the thickness of a snow layer due to viscous compression. Using this equation, the present height of the previous snow surface, which cannot be measured by simple means, was computed and the depth of daily new snow was estimated as its difference from the present measured total snow depth. The approximated results were found to be in good agreement with data measured in Tohkamachi during the three winters from 1992-93 to 1994-95. The standard deviation was $1.71 \mathrm{~cm}$ and the maximum difference between estimated values and observed values was $\pm 8 \mathrm{~cm}$.
\end{abstract}

\section{INTRODUCTION}

The depth of new snow deposited during a particular time interval is an important piece of practical information for operational snow removal from roads, the prediction of snow avalanches and other applications. But, the depth of new snow still cannot be measured automatically and is obtained manually by measuring the snow depth deposited on a snow board cleared and set on the snow surface at regular intervals.

Since the snow cover is compacted continuously due to its own weight, the depth of newly deposited snow from the previous time-step to the present time is not equal to the difference of the total snow depth during that interval. It is the difference between the height of the present snow surface and the present compacted height of the previous snow surface. The former can be measured automatically but the latter cannot. Hence, in this paper we consider a method for computing the latter from precipitation data measured automatically, on the basis of the viscous compression theory of dry snow developed by Bader (1954), Kojima (1957, 1967), Herron and Langway(1980), Motoyama and Kojima (1985) and Endo and others (1990).

In this paper, the depth of daily new snow is estimated and compared with data measured during the three winters from 1992-93 to 1994-95.

\section{ESTIMATING DEPTH OF DAILY NEW SNOW}

\section{Change in thickness of a snow layer by viscous com- pression}

In order to compute the evolution of total snow depth with time or the depth-density profile of the snow cover by viscous compression, it is necessary to know the relationship between the compressive viscosity $\eta$ and the density $\rho$ of snow.

Kojima (1957, 1958, 1967) has found that the relation between these factors for dry fine-grained snow within a density range $100-500 \mathrm{~kg} \mathrm{~m}^{-3}$ can be expressed as

$$
\eta=\eta_{0} \exp (k \rho)
$$

where $\eta_{0}$ and $k$ are constants. But, it has been pointed out recently by Nakamura (1987) and Kajikawa and Ono (1990) that the values $\eta_{0}$ and $k$ in the density range of less than about $100 \mathrm{~kg} \mathrm{~m}^{-3}$ are different from those in other ranges. This is inconvenient for the computation of snow depth or snow density.

Then, Endo and others (1990) re-investigated this relation and indicated that $\eta$ could be expressed by the following power function of $\rho$ for dry snow with a density range $40-300 \mathrm{~kg} \mathrm{~m}^{-3}$ and a snow temperature of $0^{\circ}$ to $-5^{\circ} \mathrm{C}$ :

$$
\eta=C \rho^{\mathrm{a}}
$$

where $C \approx 0.392 \mathrm{Pas}\left(\mathrm{kg} \mathrm{m}^{-3}\right)^{-a}$ and $a \approx 4$ (Endo and others, 1990). The value $C$ is considered to be dependent on snow temperature and the shape of the snow crystals. Endo $(1992,1993)$ has shown that an approximation of snow depth or snow density is possible by using this equation. It has been used to predict direct-action avalanches.

On the other hand, the compressive viscosity of wet snow is known generally to be less than that of dry snow, when the other conditions of snow, for instance, wet-snow density, grain shape and others are the same. Kojima (1967) has found that, if $\eta$ is related to dry-snow density $\rho_{\text {dry }}$ which is obtained by subtracting the contribution of free water from the wet-snow density, the relation for wet 


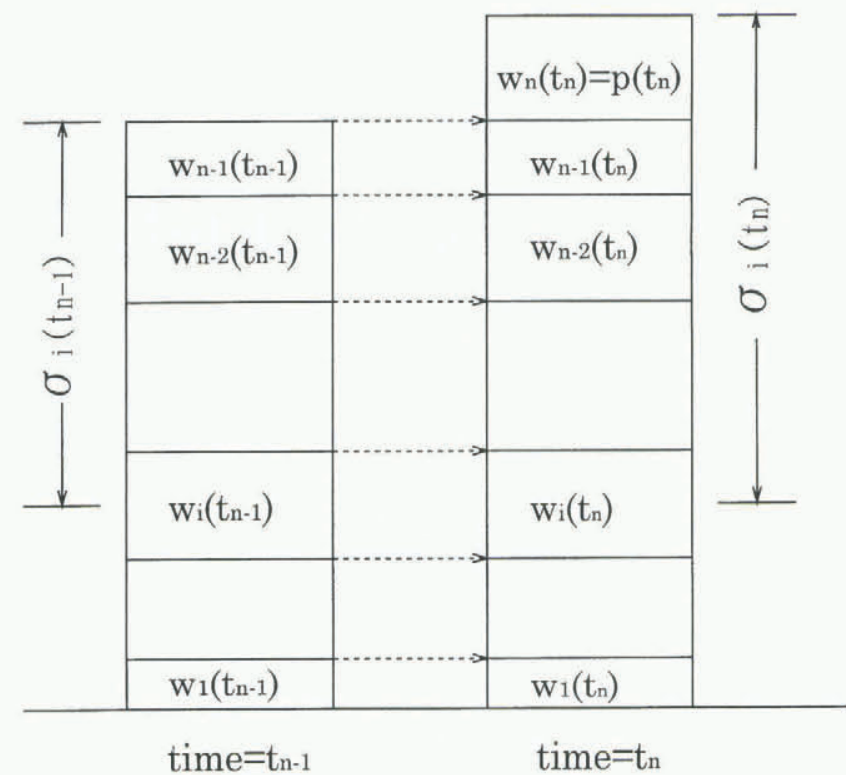

Fig. 1. Weight of each snow layer at time $t_{n-1}$ and $t_{n}$ and the stresses exerted on a column of $i$ layer.

snow with a free-water content of less than $5 \%$ is almost the same as that for dry snow of $0^{\circ} \mathrm{C}$. However, the relation for very wet snow is unknown.

Thus, we have assumed the following equation as the relation between $\eta$ and $\rho_{\text {dry }}$ (cf. Endo and others, 1990):

$$
\eta=C\left(\rho_{\mathrm{dry}}\right)^{a}
$$

where $C$ and $a$ are constants as described previously.

Now, we consider a thin snow layer called the $i$ layer which was deposited from time $t_{i-1}$ to $t_{i}$. Let the thickness of the $i$ layer at time $t\left(>t_{i}\right)$ be $h_{i}(t)$, and let the wet-snow mass of the $i$ layer per unit horizontal area and mass of free water contained in it at time $t$ respectively, be $w_{i}(t)$ and $q_{i}(t)$. Then, the dry density $\left\{\rho_{i}(t)\right\}_{\text {dry }}$ of the $i$ layer at time $t$ is

$$
\left\{\rho_{i}(t)\right\}_{\mathrm{dry}}=\frac{\left\{1-\alpha_{i}(t)\right\} w_{i}(t)}{h_{i}(t)}
$$

where $\alpha_{i}(t)$ is the free-water content by mass, of the $i$ layer at time $t$ and this is given by $\alpha_{i}(t)=q_{i}(t) / w_{i}(t)$. If the $i$ layer of thickness $h_{i}(t)$ at time $t$ is compressed by $\mathrm{d} h_{i}(t)$ in a short time interval $\mathrm{d} t$ by the normal stress $\sigma_{i}(t)$ exerted on the $i$ layer, the compressive viscosity $\eta(t)$ is denoted by

$$
\eta_{i}(t)=\sigma_{i}(t)\left(\frac{-\mathrm{d} h_{i}(t)}{h_{i}(t) \mathrm{d} t}\right)^{-1} .
$$

Substituting Equations (2) and (3) into the above equation and, integrating both sides from the previous time $t_{n-1}$ to the present time $t_{n}$ after separating the variables, the thickness $h_{i}^{\prime}(t)$ of the $i$ layer at the present time $t_{n}$ due to viscous compression is given by

$$
\begin{aligned}
h_{i}^{\prime}\left(t_{n}\right) & =h_{i}\left(t_{n-1}\right) \\
& \left\{1+\left(\frac{a}{C}\right) \frac{h_{i}\left(t_{n-1}\right)^{a}}{\left[\left\{1-\alpha_{i}\left(t_{n-1}\right)\right\} w_{i}\left(t_{n-1}\right)\right]^{a}} Q_{i}\left(t_{n-1}, t_{n}\right)\right\}^{-\frac{1}{a}}
\end{aligned}
$$

We assume that the mass $\left\{1-\alpha_{i}\left(t_{n-1}\right)\right\} w_{i}\left(t_{n-1}\right)$ of the ice part, except for the water in the $i$ layer, is unchanged from time $t_{n-1}$ to $t_{n}$.

Here, $h_{i}\left(t_{n-1}\right), w_{i}\left(t_{n-1}\right)$ and $\alpha_{i}\left(t_{n-1}\right)$ are the thickness, total mass and free-water content of the $i$ layer at time $t_{n-1}$. As shown in Figure $1, Q_{i}\left(t_{n-1}, t_{n}\right)$ is the time integration of normal stress $\sigma_{i}(t)$ exerted on the $i$ layer from time $t_{n-1}$ to $t_{n}$ :

$$
Q_{i}\left(t_{n-1}, t_{n}\right)=\int_{t_{n-1}}^{t_{n}} \sigma_{i}(t) \mathrm{d} t .
$$

Here, taking an interval $\Delta t$ between time steps $0, t_{1}, \ldots$, $t_{n-1}$ and $t_{n}$ to be short enough, we assume that changes in thickness, total mass and free-water content in each snow layer, due to snow melting and percolation of meltwater,

\section{Snow fall}

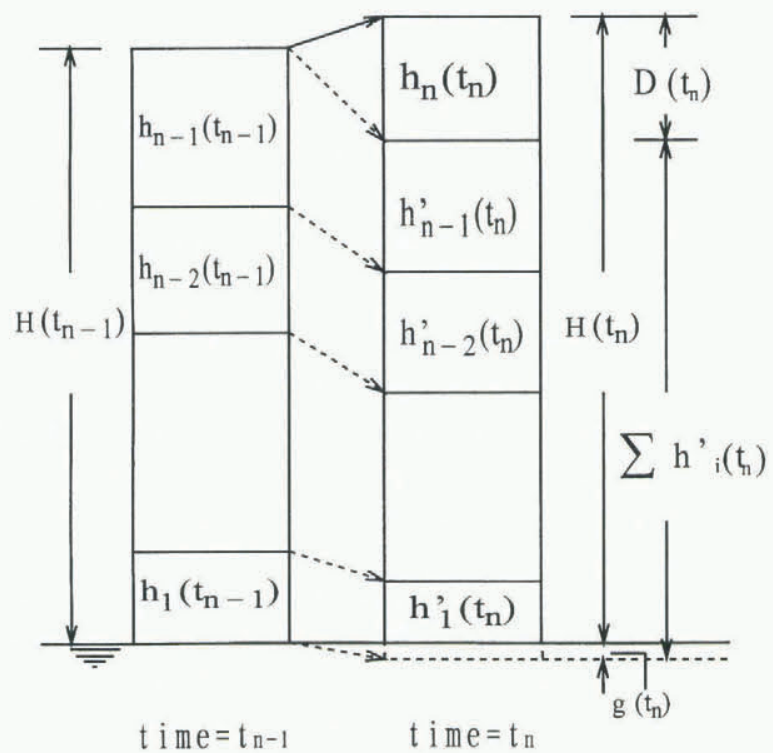

\section{Snow ablation}

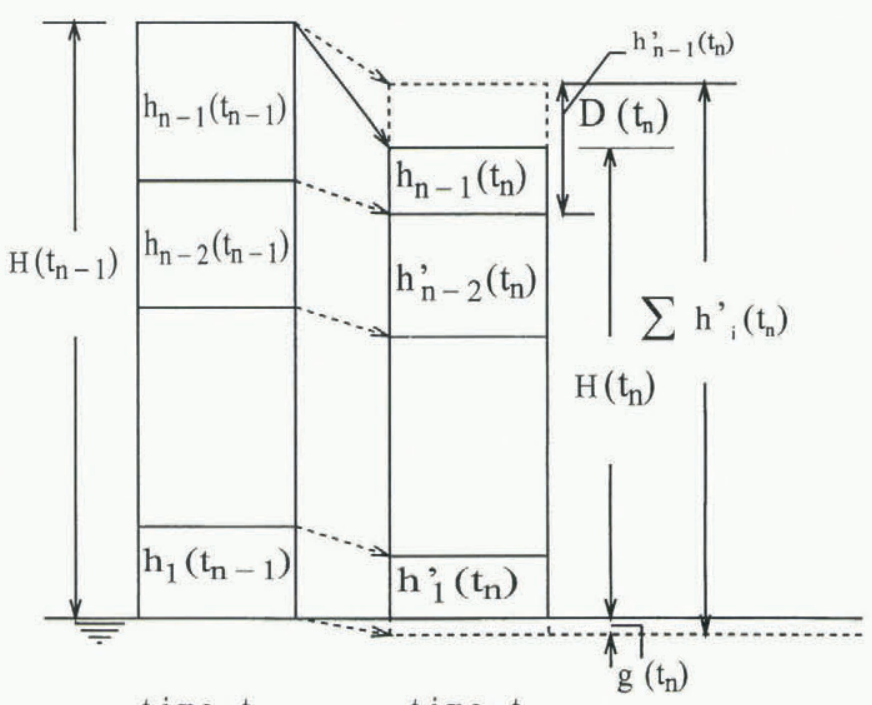

Fig. 2. Estimation method for the depth of snow accumulation and ablation. We assume that $D\left(t_{n}\right)$ indicates the depth of snow accumulation if $D\left(t_{n}\right)>0$ and snow ablation if $D\left(t_{n}\right)<0$. 
can be calculated separately using the change in thickness due to the viscous compression given by Equation (6).

Then, $Q_{i}\left(t_{n-1}, t_{n}\right)$ is approximated by

$$
Q_{i}\left(t_{n-1}, t_{n}\right)=\left\{\frac{w_{i}\left(t_{n-1}\right)}{2}+\sum_{i=i+1}^{n-1} w_{i}\left(t_{n-1}\right)+\frac{p\left(t_{n}\right)}{2}\right\} g \Delta t
$$

where $p\left(t_{n}\right)$ is the amount of precipitation deposited in the form of snow or rain from time $t_{n-1}$ to $t_{n}$, and $g$ is the gravitational acceleration.

Equations (5) and (7) show that the thickness $h_{i}^{\prime}\left(t_{n}\right)$ of each layer at the present time $t_{n}$, resulting from viscous compression, is given by the precipitation amount $p\left(t_{n}\right)$ at the present time-step and the height $h_{i}\left(t_{n-1}\right)$, the total mass $w_{i}\left(t_{n-1}\right)$ and the free-water content $\alpha_{i}\left(t_{n-1}\right)$ of each layer at the previous time-step $t_{n-1}$.

\section{Calculation of new snow depth}

Total snow depth changes by snow accumulation, ablation and viscous compression. As shown in Figure 2, we assume that snow accumulation and ablation take place, after the snow cover at time $t_{n-1}$ changes its height solely by viscous compression and settling to a sum of all $h_{i}^{\prime}\left(t_{n}\right)$. Also, we assume that the wind is so calm that it hardly transports snow particles on the snow surface such as at our site (average wind speed of $1.1 \mathrm{~m} \mathrm{~s}^{-1}$ ). In this case, snow accumulation and ablation occur, respectively, by snowfall and snow melting. Then, we consider the following index $D\left(t_{n}\right)$ :

$$
D\left(t_{n}\right)=H\left(t_{n}\right)+g\left(t_{n}\right)-\sum_{i=1}^{n-1} h_{i}^{\prime}\left(t_{n}\right) \approx H\left(t_{n}\right)-\sum_{i=1}^{n-1} h_{i}^{\prime}\left(t_{n}\right)
$$

where $H\left(t_{n}\right)$ is the total snow depth measured at time $t_{n}$, and $\Sigma h_{i}^{\prime}\left(t_{n}\right)$ is the total snow cover estimated as a result of viscous compression. And $g\left(t_{n}\right)$ is the thickness of snow melted on the ground from time $t_{n-1}$ to $t_{n}$. This melt thickness has been neglected because measured $g\left(t_{n}\right)$, using a snow lysimeter, is less than $0.1 \mathrm{~cm} \mathrm{~d}^{-1}$ of snow.

If new snow is deposited during the time interval from time $t_{n-1}$ to $t_{n}$ without melting of the old snow surface at time $t_{n-1}, D\left(t_{n}\right)$ is positive and the value of $D\left(t_{n}\right)$ gives thickness a $h_{n}\left(t_{n}\right)$ of the newly deposited $n$ layer, as shown in Figure 2. In an opposite case, that snow melting takes place on the surface without snowfall, $D\left(t_{n}\right)$ is negative, indicating the thickness of snow melted on the surface. Also, even in the case that both snowfall and snow melting take place during the interval, if snow melting occurs after new snow is deposited, $D\left(t_{n}\right)$ shows the thickness of new snow in $D\left(t_{n}\right)>0$ and of melted snow in $D\left(t_{n}\right)<0$.

However, if new snow is deposited after the snow surface at time $t_{n-1}$ is melted, we cannot obtain the respective thickness of them from $D\left(t_{n}\right)$.

But, these cases are possible only at the beginning of a snowfall. If we take the time interval to be short enough, the ratio of occurrence of these cases compared to all becomes small.

Hence, taking the time interval $\Delta t$ as 1 hour, we assume that $D\left(t_{n}\right)$ gives the thickness of new snow in the case of $D\left(t_{n}\right)>0$ and the thickness of snow melted on the surface in the case of $D\left(t_{n}\right)<0$. In the case of $D\left(t_{n}\right)>0$, the precipitation $p\left(t_{n}\right)$, considered as the amount of snow, gives a mass $w_{n}\left(t_{n}\right)$ of the $n$ layer at a time $t_{n}$. Free-water content of the new snow is supposed to be 0 , because it is unknown. Thus, height, mass and water content of the $n$ layer are as follows:

$h_{n}\left(t_{n}\right)=D\left(t_{n}\right), w_{n}\left(t_{n}\right)=p\left(t_{n}\right), \alpha_{n}\left(t_{n}\right)=0$ for $D\left(t_{n}\right)>0$.

In the other case of $D\left(t_{n}\right)<0$, we suppose that the precipitation $p\left(t_{n}\right)$ is the same amount of rain as the surface is melting. In this case, the $k$ layer located at depth $D\left(t_{n}\right)$ of snow melted from the snow surface satisfies the following equation:

$$
\sum_{i=k}^{n-1} h_{i}^{\prime}\left(t_{n}\right)<-D\left(t_{n}\right)<\sum_{i=k-1}^{n-1} h_{i}^{\prime}\left(t_{n}\right) .
$$

As a result of snow melting, the thickness $h_{i}\left(t_{n}\right)$ of each layer at time $t_{n}$ becomes

$$
\begin{aligned}
h_{i}\left(t_{n}\right) & =0 \quad \text { for } i=n, i=1, \ldots, k, \\
h_{k-1}\left(t_{n}\right) & =\sum_{i=k-1}^{n-1} h_{i}^{\prime}\left(t_{n}\right)+D\left(t_{n}\right), \\
h_{i}\left(t_{n}\right) & =h_{i}^{\prime}\left(t_{n}\right) \text { for } i=k-2, k-3, \ldots, 1 .
\end{aligned}
$$

Also, mass $m\left(t_{n}\right)$, containing free water, of wet snow melted on the surface is given by

$$
m\left(t_{n}\right)=\sum_{i=k}^{n-1} w_{i}\left(t_{n-1}\right)+\left\{1-\frac{h_{k-1}\left(t_{n}\right)}{h_{k-1}^{\prime}\left(t_{n}\right)}\right\} w_{k-1}\left(t_{n-1}\right) .
$$

We assume that this meltwater $m\left(t_{n}\right)$ is distributed with the precipitation $p\left(t_{n}\right)$ in the lower snow layers, according to such a simple tank model that free water contained in a snow layer can percolate into the lower layer only in the case when its free-water content $\alpha_{i}\left(t_{n}\right)$ exceeds the maximum value $\alpha_{\max }$. Then, we can determine that mass $w_{i}\left(t_{n}\right)$ and free-water content $\alpha_{i}\left(t_{n}\right)$ of each snow layer at time $t_{n}$.

If we compute the new snow depth from time-step 1 by such a method, we can obtain thickness, mass and freewater content of each snow layer at the present time $t_{n}$, using the values of total snow depth and precipitation measured at each time-step from time $t_{1}$ to $t_{n}$. In this paper, as we take $\Delta t$ as 1 hour, depth of hourly new snow at time $t_{n}$ is given by thickness $h_{n}\left(t_{n}\right)$ of the $t_{n}$ layer and that of daily new snow is given by

$$
D\left(t_{n}\right)_{\text {day }}=\sum_{i=n-23}^{n} h_{i}\left(t_{n}\right)
$$

where $D\left(t_{n}\right)_{\text {day }}$ is the depth of daily new snow at time $t_{n}$.

\section{OBSERVATION SITE AND CLIMATE}

We made a system for computing and displaying depth of daily new snow using the above-mentioned method, by using values of total snow depth and precipitation measured hourly by an ultrasonic snow-depth meter SL-340 (minimum digit $0.1 \mathrm{~cm}$ ) of the Kaijo Co. Ltd and a rain- and snow-gauge (minimum digit $0.5 \mathrm{~mm}$ of water) of the Yokogawa Weathac Corporation, respectively.

To evaluate the depth of daily new snow estimated by this system, we set a snow board on the snow surface at 09.00 each morning and measured the depth of new snow deposited on the board during 24 hours.

These measurements were made at the Tohkamachi experimental station during three winters from 1992-93 to 1994 95. This site is situated about $190 \mathrm{~km}$ northwest from 
Tokyo and located at $37^{\circ} 08^{\prime} \mathrm{N}, 138^{\circ} 46^{\prime} \mathrm{E}$ at an altitude of about $200 \mathrm{~m}$. Monthly average air temperatures of these winters were $3.2^{\circ} \mathrm{C}$ in December, $0.5^{\circ} \mathrm{C}$ in January, $0.9^{\circ} \mathrm{C}$ in February and $2.8^{\circ} \mathrm{C}$ in March, and snow layers were in wet conditions during most periods. The average wind speed of the winters was $1.1 \mathrm{~m} \mathrm{~s}^{-1}$ and snowdrift rarely occurred. Maximum snow depths were $172 \mathrm{~cm}$ in $1992-93,163 \mathrm{~cm}$ in 1993-94 and $226 \mathrm{~cm}$ in 1994-95.

\section{COMPARISON BETWEEN COMPUTED AND MEA- SURED DEPTH OF DAILY NEW SNOW}

In order to optimize the values of $C$ and $a$ in Equation (2), we set the maximum free-water content $\alpha_{\max }$ in each snow layer, and we computed the depth of the daily new snow for various values of $a$, using the following relations:

$$
C=0.392 \mathrm{Pas}\left(\mathrm{kg} \mathrm{m}^{-3}\right)^{-a}, \alpha_{\max }=0.15
$$

and compared with the measured depth.

Table 1. Standard deviation of estimated snow depth depending on the chosen value of a for three years of observation (assuming $C=0.392$ Pas $\left(\mathrm{kg} \mathrm{m}^{-3}\right)^{-a}$ and $\alpha_{\max }=0.15$ ) (A) Using all data; (B) using data exceeding $10 \mathrm{~cm}$

A. Standard deviation with all data

\begin{tabular}{cccccc}
\hline & \multicolumn{5}{c}{ Standard deviation $(\mathrm{cm})$} \\
Year $\backslash a$ & 3.4 & 3.5 & 3.6 & 3.8 & 4.0 \\
& & & & & \\
\hline $1992-93$ & 1.73 & 1.62 & 1.52 & 1.42 & 1.45 \\
$1993-94$ & 1.79 & 1.76 & 1.75 & 1.82 & 1.95 \\
$1994-95$ & 1.80 & 1.79 & 1.84 & 1.99 & 2.16 \\
Average & 1.77 & 1.72 & 1.71 & 1.74 & 1.85 \\
\hline
\end{tabular}

B. Standard deviation with data exceeding $10 \mathrm{~cm}$

\begin{tabular}{cccccc}
\hline \multicolumn{5}{c}{ Standard deviation $(\mathrm{cm})$} \\
Year $\backslash a$ & 3.4 & 3.5 & 3.6 & 3.8 & 4.0 \\
& & & & & \\
\hline $1992-93$ & 2.64 & 2.42 & 2.24 & 2.07 & 2.14 \\
$1993-94$ & 2.91 & 2.86 & 2.83 & 2.95 & 3.09 \\
$1994-95$ & 2.68 & 2.72 & 2.84 & 3.15 & 3.45 \\
Average & 2.74 & 2.67 & 2.66 & 2.79 & 2.98 \\
\hline
\end{tabular}

Table 1 shows the standard deviation $\delta$ of the computed depth for the various values of $a$, where $\delta$ is calculated by the root-mean-square of the difference between approximated and observed new snow depth. As shown in Table 1, the standard deviation is smallest when 3.6 is used for $a$ in both cases. Therefore, we computed the depth of daily new snow taking $a=3.6$.

The computed results are shown in Figure 3, where the approximated depth vs the measured depth is shown. In Figure 4, a comparison of the measured and computed depth is shown for January of each winter. We can see from these figures that the computed depth is in a good agreement with the measured depth and its maximum difference is about $\pm 8 \mathrm{~cm}$.

The maximum free water content $\alpha_{\max }$ by mass is con80

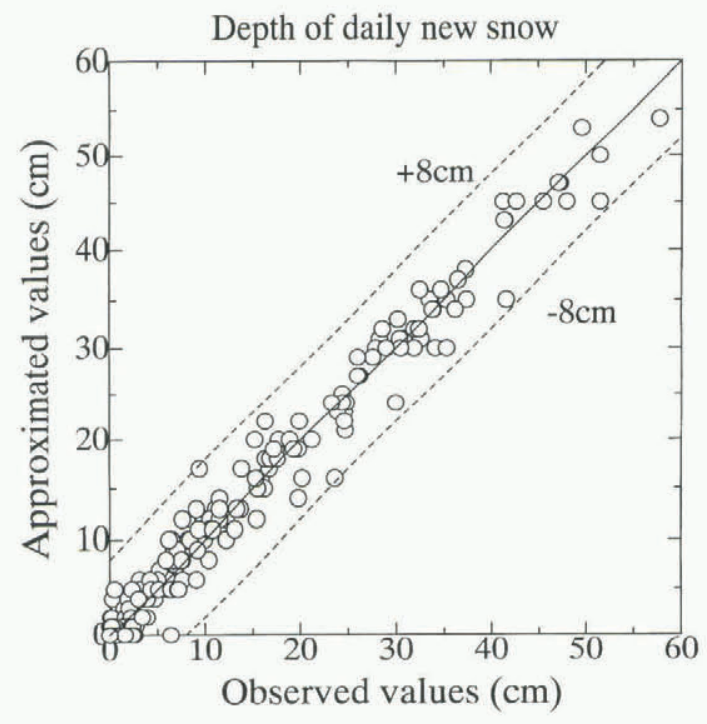

Fig. 3. Relationship between approximated and observed depth of daily new snow for the winters of 1992 -93, 1993-94 and 1994-95.
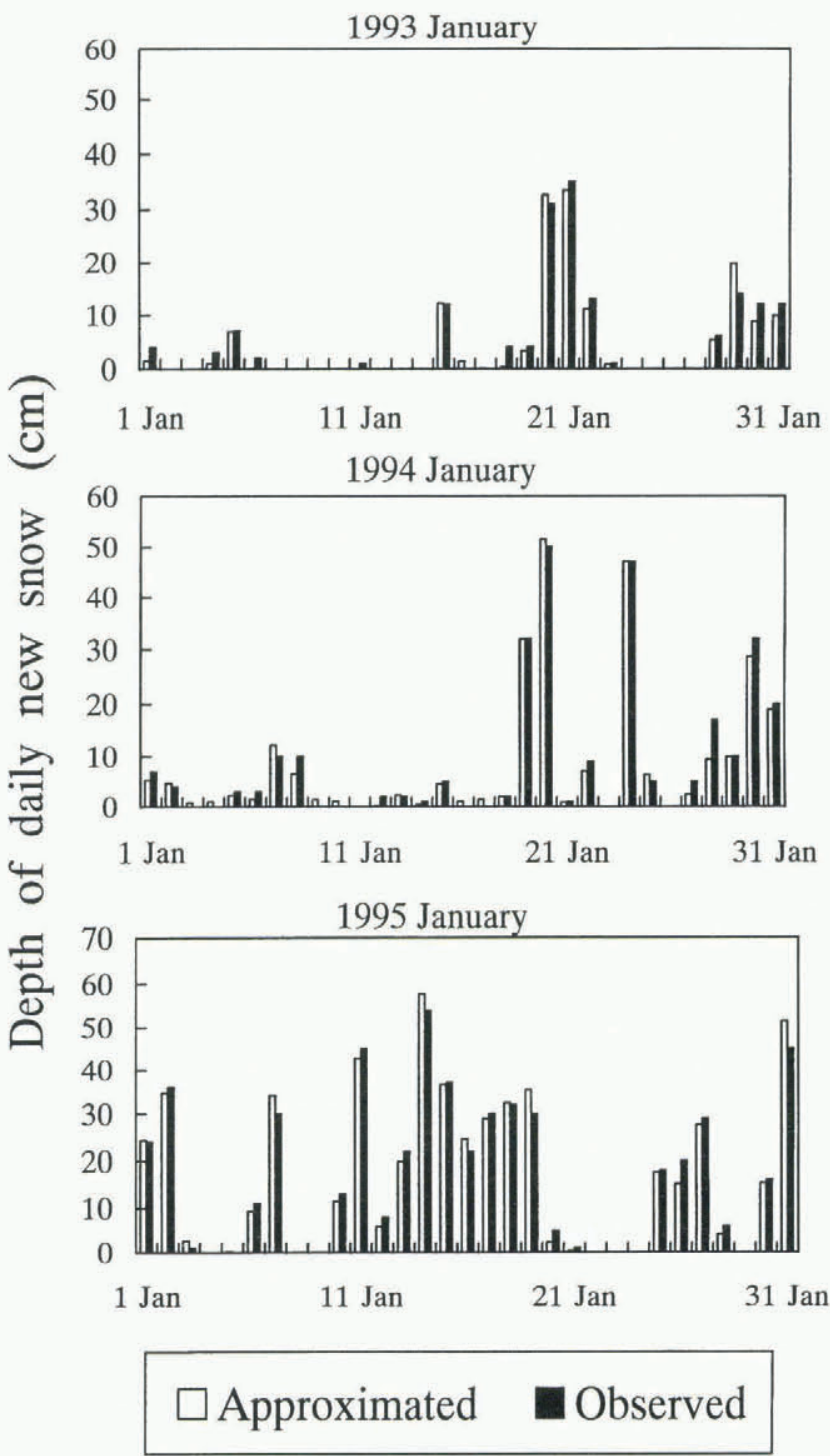

Fig. 4. Comparison of approximated and observed depth of daily new snow for January. 
sidered to be $0.10-0.20$, depending on grain-size and grain shape (Yoshida, 1967). There was little difference between the depths of daily new snow computed for maximum freewater content from $\alpha_{\max }=0.10$ to $\alpha_{\max }=0.20$.

\section{DISGUSSION}

\section{Comparison with conventional estimation methods of new snow depth}

Most of the local observation stations of the Japanese Meteorological Agency use two conventional methods, based on differences of total snow depth measured automatically, to estimate the depth of daily new snow; the first one is the method of substituting daily change of total snow depth for depth of daily new snow, and the second one is the method of estimating the depth of daily new snow by summing the positive increment of hourly snow-depth changes.

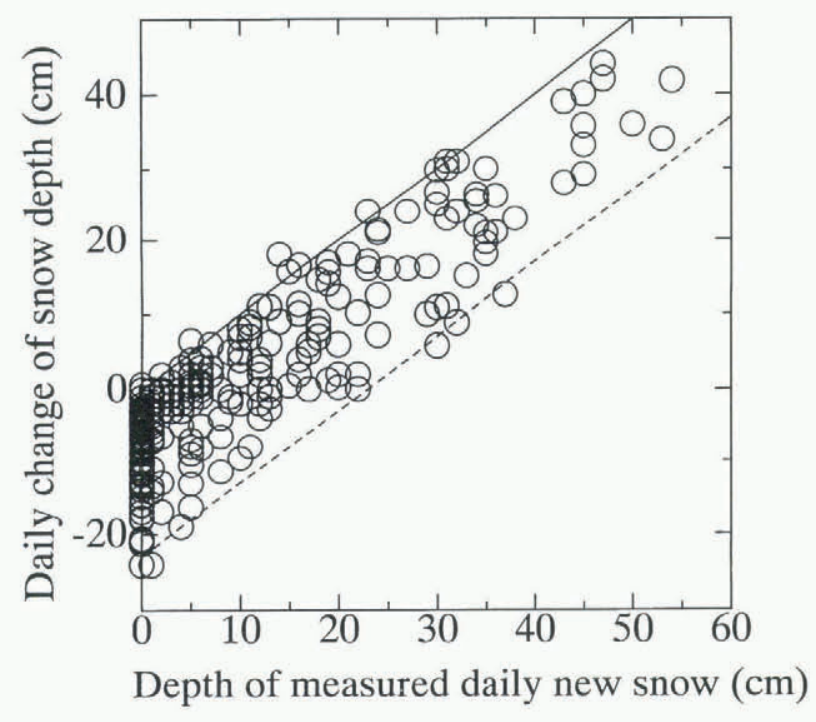

Fig. 5. Relationship between daily change in total snow depth and conventionally measured depth of daily new snow.

We investigated the error of estimation using these two methods and compared them with our estimate by the viscous compression model, using the same data of the three winters from 1992-93 to 1994-95. Figure 5 shows the relationship between daily change of total snow depth and the conventionally measured depth of daily new snow. As shown in this figure, the errors of daily difference of snow depth are usually negative and its maximum error is $-23 \mathrm{~cm}$; the standard deviation is $9.72 \mathrm{~cm}$. Such large negative errors are mainly caused by viscous compression of the snow cover.

The estimation method by summing positive change is considered to revise the negative errors due to viscous compression by removing the negative change of hourly snow depth. The relationship between the values estimated by this method and the conventionally measured depths of daily new snow is shown in Figure 6. Using this revision, the estimated values shown in Figure 6 are distributed equally around a solid line which indicates $y=x$. However, its maximum error is $\pm 15 \mathrm{~cm}$ and standard deviation is $4.52 \mathrm{~cm}$.

These results show that estimates using the viscous compression model method are much more accurate than the other two conventional methods.

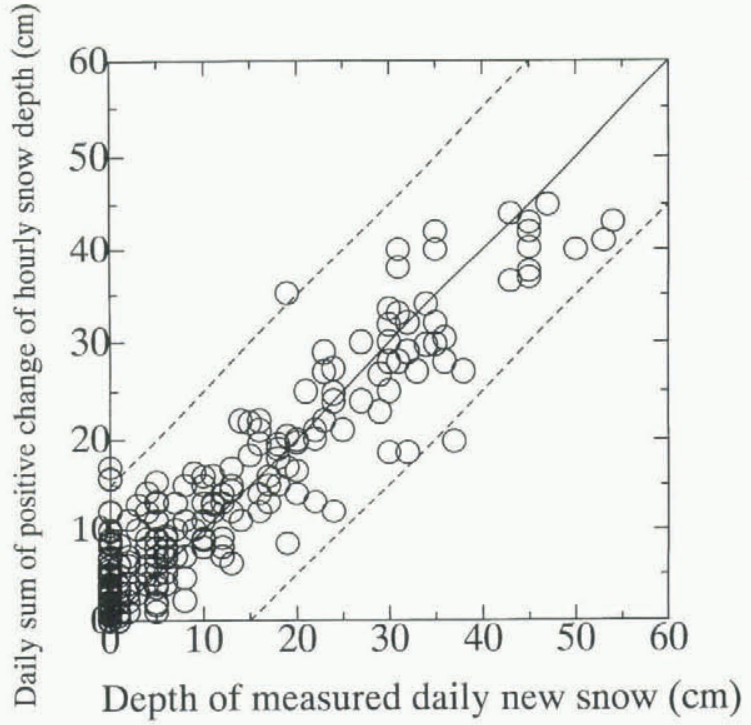

Fig. 6. Relationship between the daily sum of positive changes in hourly snow depth and the conventionally measured depth of daily new snow.

Relationship between compressive viscosity and dry-snow density

Taking $C=0.392 \mathrm{~Pa} \mathrm{~s}\left(\mathrm{~kg} \mathrm{~m}^{-3}\right)^{-\mathrm{a}}$, we determined the constant $a=3.6$ in Equation (2) in order to minimize the errors of the estimated depth of daily new snow.

The result obtained is shown in Figure 7 as the plot of log $\eta$ against the dry-snow density, together with the values measured for dry, fine-grained snow below $0^{\circ} \mathrm{C}$ by other researchers (Kojima, 1967; Shinojima, 1967; Nakamura, 1988; Endo and others, 1990; Kajikawa and Ono, 1990). The solid line represents the relation used in this paper and the broken lines those by the other authors. As shown in this figure, the solid line is not too far from the broken lines. Hence, the values of $C$ and $a$ used in this paper are considered to be appropriate values.

\section{CONCLUSIONS}

We have derived a method of approximating the depth of

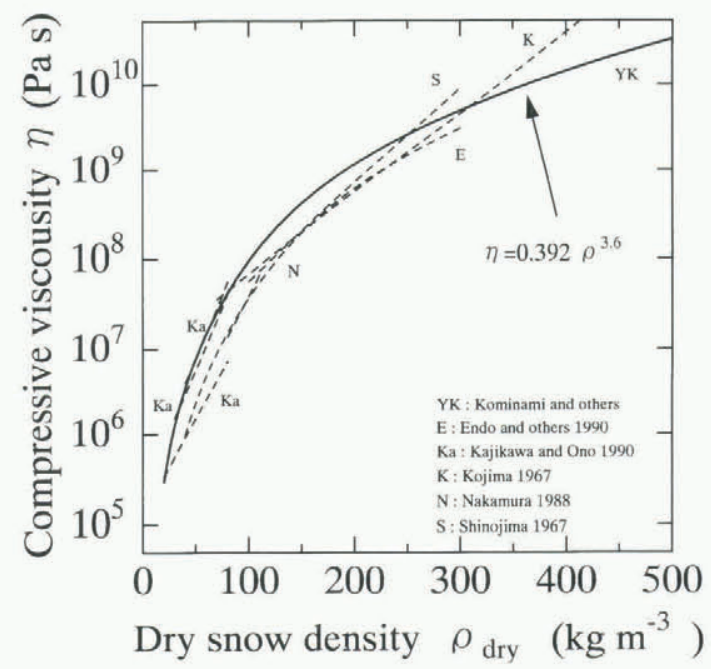

Fig. 7. Relationship between compressive viscosity and drysnow density. 
daily new snow by using data of hourly total snow depth and hourly precipitation, based on a viscous compression model of snow.

As shown in Figure 3, the approximated depth of daily new snow was found to be in good agreement with the depth measured with a snow board in Tohkamachi during three winters 1992-93 to 1994-95. The standard deviation for this "calibration" data set was $1.71 \mathrm{~cm}$ and maximum difference between the approximated values and the observed values was $\pm 8 \mathrm{~cm}$.

\section{REFERENCES}

Bader, H. 1954. Sorge's Law of densification of snow on high polar glaciers. 7. Glaciol., 2 (15), 319-323.

Endo, Y. 1992. Time variation of stability index in new snow on slopes. In Proceedings. Japan - U.S. Workshop on Snow Avalanche, Landslide, Debris Flow Prediction and Control, 30 September - 2 October 1991, Tsukuba, Japan. Science and Technology Agency. National Research Institute for Earth Science and Disaster Prevention, 85-94.

Endo, Y. 1993. [Forecasting of direct-action avalanches in terms of snow accumulation rates.] Seppyo, 7. Jpn. Soc. Snow Ice, 55(2), 113-120. [In Japanese.]

Endo, Y., Y. Ohzeki and S. Niwano. 1990. [Relation between compressive viscosity and density of low-density snow.] Seppyo, J. Jpn. Soc. Snow Ice, 52 (4), 267-274. [InJapanese with English summary.]

Herron, M. M. and C. C. Langway, Jr. 1980. Firn densification: an empirical model. f. Glaciol., 25(93), 373-385.

Kajikawa, M. and N. Ono. 1990. [Relationship between the compactive viscosity of new snow and the shape of snow crystals.] Seppyo, 7. Jpn. Soc. Snow Ice, 52 (4), 283-287. [InJapanese with English summary.]

Kojima, K. 1957. [Viscous compression of natural snow layers. 3.] Low Temp. Sci., Ser. A 16, 167-196. [InJapanese with English summary.]

Kojima, K. 1958. [Viscous compression of natural snow layers. 4.] Low Temp. Sci., Ser. A 17, 53-64. [In Japanese with English summary.]

Kojima, K. 1967. Densification of seasonal snow cover. In Oura, H., ed. Physics of snow and ice. Vol. 1, Part 2. Sapporo, Hokkaido University. Institute of Low Temperature Science, 929-952.

Motoyama, H. and K. Kojima. 1985. [Estimation model for the depth of a dry snow cover based on the viscous compression theory of seasonal snow cover.] Low Temp. Sci., Ser. A 44, 15-25. [In Japanese with English summary.]

Nakamura, H. 1987. Studies on the settlement force of snow as a generation mechanism. Report of the National Research Center for Disaster Prevention 41, $361-385$.

Shinojima, K. 1967. Study on the visco-elastic deformation of deposited snow. In Ōura, H., ed. Physics of snow and ice. Vol. 1, Part 2. Sapporo, Hokkaido University. Institute of Low Temperature Science, 875-907.

Yoshida, Z. 1967. Free water content of wet snow. In Oura, H., ed. Physics of snow and ice. Vol. 1, Part 2. Sapporo, Hokkaido University. Institute of Low Temperature Science, $773-784$. 